\title{
A REAPPRAISAL OF ACUTE TRAUMATIC CENTRAL CORD SYNDROME
}

\author{
W. F. MERRIAM, T. K. F. TAYLOR, S. J. RUFF, M. J. McPHAIL \\ From the Department of Orthopaedics and Traumatic Surgery, Royal North Shore Hospital, Australia
}

\begin{abstract}
A review of 77 patients with traumatic central cord syndrome revealed that atypical variations are more common than the existing literature suggests and that these may be seen in a wide variety of acute injuries to the cervical spine. In general the outcome is good; a favourable prognosis on admission is suggested by good hand function, hyperpathia, Lhermitte's sign and normal perianal sensation. The study has highlighted the value of regular muscle charting and has cast doubt on previous neuroanatomical assumptions about the syndrome.
\end{abstract}

Central cord syndrome is the commonest of the incomplete traumatic cervical cord syndromes, the others being the Brown-Séquard syndrome and the anterior cord syndrome. As originally defined by Schneider, Cherry and Pantek (1954), the central cord syndrome is characterised by motor impairment which is disproportionately greater in the upper limbs than in the lower, by bladder dysfunction (most often urinary retention) and by a variable degree of sensory loss below the level of the cord lesion. These authors and others (Taylor and Blackwood 1948) found the syndrome to be most common in older subjects with cervical spondylosis , and hyperextension injuries. A number of series included no patients with bony injuries but it had been noted originally that the syndrome did also occur with fractures and fracture-dislocations; subsequently this association received scant attention. This report aims to draw attention to the variability of the central cord syndrome in a wide range of injuries to the cervical spine, and to ascertain which clinical features may be of prognostic significance.

\section{PATIENTS AND METHOD}

Between the years 1958 and 1984, 489 patients with cervical spine injuries were admitted to the Spinal Injuries Unit at the Royal North Shore Hospital of

W. F. Merriam, FRCS, Senior Registrar

Royal Orthopaedic Hospital, Woodlands, Northfields, Birmingham B32 2AP, England.

T. K. F. Taylor, FRCS, FRCS Ed, FRACS, Professor of Orthopaedics and Traumatic Surgery

S. J. Ruff, FRACS, Visiting Medical Officer

M. J. McPhail, Dip. Phty, Head Physiotherapist

Royal North Shore Hospital, St Leonards, N.S.W. 2065, Australia.

Requests for reprints should be sent to Professor T. K. F. Taylor.

(C) 1986 British Editorial Society of Bone and Joint Surgery $0301-620 \mathrm{X} / 86 / 5152 \$ 2.00$
Sydney, the major referral unit for spinal cord injuries for most of New South Wales, some other regions of Australia, as well as for scattered islands in the southwest Pacific basin. Although referrals from this wide geographical area often made long-term follow-up impossible, 77 patients who presented with a form of the central cord syndrome have been reviewed. They formed $15.7 \%$ of all cervical spine injuries. All patients who, on admission, had more motor loss in the upper limbs than the lower were included. Had all the criteria put forward by Schneider et al. (1954) been rigidly employed, then only one patient would have been included, a man over 50 years of age with spondylotic changes in the cervical spine but no bony injury. Forty-six patients $(60 \%)$ were recalled for examination, and most of the other cases had been followed up for more than two years (mean 30.9 months).

Where possible, information (including muscle charts) was collated for five time intervals : on admission, between 48 hours and one week, between one week and six weeks, between six weeks and six months and finally between six months and two years. These intervals were chosen as appropriate from past clinical experience of rates of recovery.

\section{CLINICAL DETAILS}

Age and sex distribution. There were 68 men and 9 women in the series. Figure 1 shows the age distribution in decades, and also that just over half of the patients were under 30 at the time of injury.

Injuries. These were sustained mostly in motor vehicle accidents $(52 \%)$ or in sporting accidents $(27 \%)$. Table I shows the number and type of spinal injuries or abnormalities. No bony injury was identified in 10 patients but in five of them radiographs revealed spondylotic changes. Only one of those with spondylosis 
Table I. Spinal injuries or abnormalities found in 77 patients with traumatic central cord syndrome

\begin{tabular}{lll}
\hline & Number & Per cent \\
\hline Fracture-dislocation & 21 & 27.3 \\
Compression fracture & 19 & 24.7 \\
No bony injury & 10 & 13.0 \\
Unifacet dislocation & 9 & 11.7 \\
Bilateral facet dislocation & 4 & 5.2 \\
Subluxations & 4 & 5.2 \\
Atlas or odontoid fractures & 3 & 3.9 \\
Burst fractures & 3 & 3.9 \\
Ankylosing spondylitis + fracture & 2 & 2.5 \\
Congenital abnormality & 1 & 1.3 \\
Comminuted fracture & 1 & 1.3 \\
\hline
\end{tabular}

had a pure central cord syndrome. Figures 2 to 7 show the wide range of injuries associate with a typical central cord syndrome.

Neurological changes. The central cord syndrome was pure in 20 patients $(26 \%)$ and atypical in the other 57 $(74 \%)$. However, the neurological deficit typical of Brown-Séquard syndrome was also seen to a marked degree in 11 patients $(14.3 \%)$ and mildly in $14(18.2 \%)$. Sensory abnormalities. On admission, 38 patients $(49.4 \%)$ had normal perianal sensation, in $22(28.6 \%)$ it was impaired and was absent in five $(6.5 \%)$. This information was not available for 12 patients. Hyperpathia, an excessive sensory response to both noxious and nonnoxious stimuli, was a notable feature in 17 patients. This is distressing because it is usually a delayed response as well as an excessive one. There is also a prolonged afterreaction (Noordenbos 1959) and it occurs more frequently in the proximal parts of the upper limbs. Many of our patients could not bear the slightest touch on the involved areas, not even the pressure of bedclothes. This symptom, which might suggest root pain to those unaware of hyperpathia, gradually subsided over two to three weeks and eventually disappeared completely in all patients.

Lhermitte's sign, sudden shooting paraesthesiae like electric shocks spreading down the body or into the limbs on flexion of the neck, may present with local lesions of the cervical spinal cord, in multiple sclerosis or spondylotic myelopathy and as a sequel to head injuries. The pathogenesis of this non-specific sign is unknown. It was present in seven of our patients and tended to persist, although it was never troublesome at long-term review. Spinal canal diameter. Cervical spine radiographs of 51 patients were available for review, and in these the mean sagittal diameter of the canal at C5 was $18.1 \mathrm{~mm}$ (s.d. \pm $1.93 \mathrm{~mm}$ ). The normal diameter at this level is reported to be $17 \mathrm{~mm}$ (Wolf, Khilnani and Malis 1956), and it has

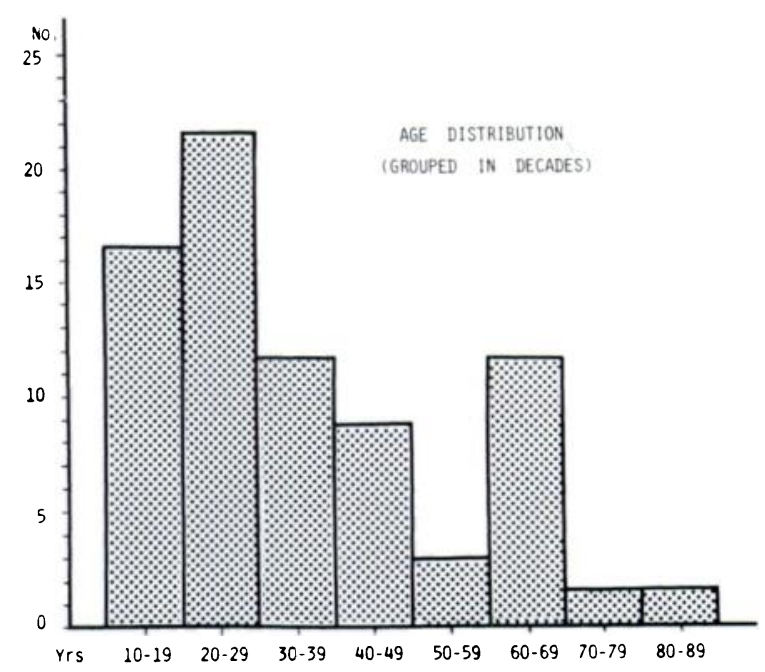

Fig. 1

Age distribution by decades of 77 patients with traumatic central cord syndrome.

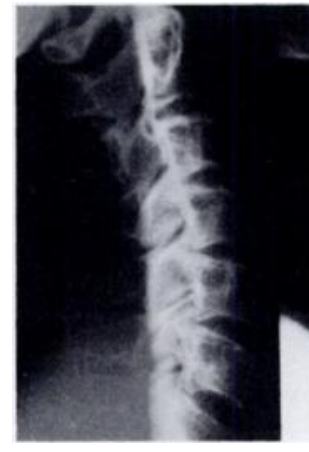

Fig. 2

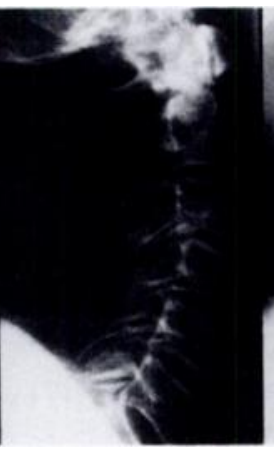

Fig. 3

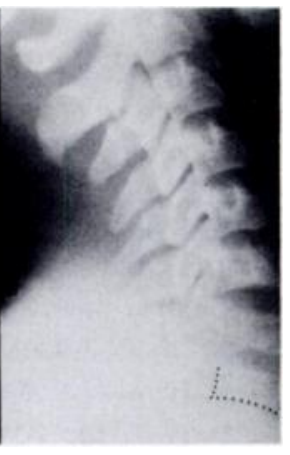

Fig. 4

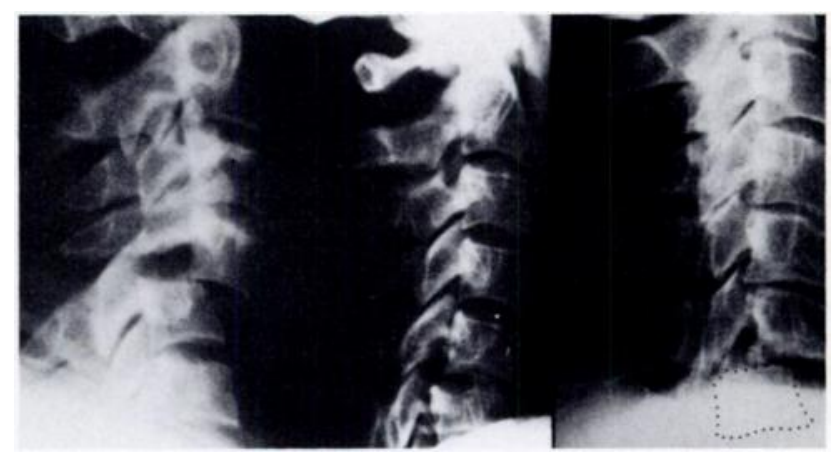

Fig. 5

Fig. 6

Fig. 7

Lateral cervical spine radiographs of six patients, each with a pure central cord syndrome. Figure 2 - A 17 -year-old youth with no bony injury and no spondylosis. Figure 3 - A 64 -year-old man with no bony injury and minimal spondylotic changes. Figure 4 - A 14-year-old boy with compression fractures of $\mathrm{C} 7$ and $\mathrm{T} 1$. Figure $5-\mathrm{A} 24$-year-old man with bilateral facet dislocations. Figure 6-A 32-year-old man with a unifacet dislocation. Figure 7 - A 60-year-old man with bilateral facet dislocations and marked spondylosis.

been suggested that the risk of myelopathy in spondylosis increases when the sagittal diameter is less than $12 \mathrm{~mm}$ (Murone 1974).

Associated injuries. A concomitant head injury was present in 13 patients, four had chest injuries and six had long-bone fractures; these injuries did not influence management significantly. 
Table II. Neurological assessment (Frankel et al. 1969)

\begin{tabular}{|c|c|}
\hline Complete $(\dot{\mathrm{A}})$ & $\begin{array}{l}\text { No motor power or sensation below the level of the } \\
\text { lesion. }\end{array}$ \\
\hline Sensory (B) & $\begin{array}{l}\text { No motor power but some sensation below the level } \\
\text { of the lesion. }\end{array}$ \\
\hline Motor useless (C) & $\begin{array}{l}\text { Some motor power below the level of the lesion but of } \\
\text { no functional use to the patient. }\end{array}$ \\
\hline Motor useful (D) & $\begin{array}{l}\text { Motor power of functional use below the level of the } \\
\text { lesion; the patient is able to walk with or without } \\
\text { aids. }\end{array}$ \\
\hline Recovery (E) & $\begin{array}{l}\text { Full motor power, normal sensation and no sphincter } \\
\text { disturbance, although reflexes may be abnormal. }\end{array}$ \\
\hline
\end{tabular}

Treatment. Because of their wide range, these injuries were managed in different ways. Anterior fusion was carried out in 19 patients and posterior fusion in 11. This simply reflects the approaches used by different surgeons, and the role of operative techniques in the management of the syndrome is not discussed in this paper.

\section{RESULTS}

In this study both the heterogeneity of the vertebral injuries and the wide range of associated neurological deficits precluded any useful breakdown into sub-groups. Instead the results were examined for trends which would indicate any factors of prognostic significance. Overall assessment. Results were simply considered as good or bad. A patient with a good result had bladder control at the final assessment with motor power better than Grade 4 on the MRC scale of 0 to 6 in each of five upper limb muscles on each side. The deltoid, biceps, triceps, extensor carpi radialis longus and the palmar interossei muscles were tested to provide a full range of segmental innervation. More than 5000 muscle gradings were available for computer-based, chi-square analysis. On this basis good results were found in 29 patients $(37.7 \%)$ while 43 patients $(55.8 \%)$ were judged to have bad results. Adequate information was not available for the categorisation of the remaining five patients.

Frankel grades. The Frankel grid is a widely employed method of representing recovery in spinal cord injury patients (Frankel et al. 1969); the gradings are shown in Table II. All our patients by definition had an incomplete lesion. In Figure 8 (data for 76 patients), the boxes with heavy lines give the number of patients with unchanged Frankel scores at follow-up. Numbers above and to the right of these indicate patients who showed improvement; there were no patients whose condition deteriorated. In all, 24 patients improved from Grade C to Grade $\mathrm{D}$ (that is, from having some motor power but no functional ability to being able to walk) and 14 improved from Grade $D$ to full functional recovery. In general, recovery followed a distinct pattern: motor power returned first to the lower limbs, followed by

\begin{tabular}{|r|r|r|r|r|}
\hline$A A$ & $A B$ & $A C$ & $A D$ & $A E$ \\
0 & 0 & 0 & 3 & 0 \\
\hline$B A$ & $B B$ & $B C$ & $B D$ & $B E$ \\
0 & 0 & 0 & 4 & 0 \\
\hline$C A$ & $C B$ & $C C$ & $C D$ & $C E$ \\
0 & 0 & 3 & 24 & 4 \\
\hline$D A$ & $D B$ & $D C$ & $D D$ & $D E$ \\
0 & 0 & 0 & 24 & 14 \\
\hline$E A$ & $E B$ & $E C$ & $E D$ & $E E$ \\
0 & 0 & 0 & 0 & 0 \\
\hline
\end{tabular}

Fig. 8

Frankel grades at initial and final assessment for 76 patients (see text and Table II).

bladder function and then by the return of motor power to the upper limbs. The return of sensory function was not concurrent with recovery of motor power.

Hand function. It is well recognised that the small muscles of the hand are profoundly affected in central cord syndrome. In the present series, of those cases in which the palmar interosseous muscles were graded at admission, 18 of 23 were in Grades 4, 5 or 6 and all had a good outcome. Only $10 \%$ of patients whose grades were 1,2 or 3 between one and six weeks after injury had good results, and this figure fell to $4 \%$ of those with Grades 1,2 or 3 at six weeks to six months. No correlation was found between interosseous weakness at follow-up and the level of the original spinal cord injury.

Bladder control. Normal bladder function had been regained by six months after injury in 50 patients $(65 \%)$; at six months $72(94 \%)$ had acceptable control of micturition but 20 , including some with normal function, described subjective abnormalities; five patients had no control over bladder function and information was not available for five others.

Sexual function. At review 28 men reported that they had regained normal sexual function but 11 had total absence. Six men had impaired erection but could ejaculate, while seven could achieve only an inadequate erection. Information was not available for the remaining 16 men. None of the patients were investigated by nocturnal penile tumescence monitoring, and it was difficult to determine whether the reported impairment

Table III. Assessment of hand function*

\begin{tabular}{lccccc}
\hline & \multicolumn{2}{l}{ Right hand } & & \multicolumn{2}{l}{ Left hand } \\
\cline { 2 - 3 } Function & 6 months & 2 years & & 6 months & 2 years \\
\hline Stiff and useless & 8.3 & 7.0 & 8.3 & 7.0 \\
Stiff and useful & 63.9 & 52.6 & 54.2 & 47.4 \\
Normal & 27.8 & 40.4 & 37.5 & 45.6 \\
\hline
\end{tabular}

- Numbers represent percentages of 77 patients 
Table IV. Time of outcome of walking, daily activities and return to work

\begin{tabular}{|c|c|c|c|c|c|c|}
\hline \multirow[b]{2}{*}{ Time interval } & \multicolumn{2}{|c|}{ Walking unaided } & \multicolumn{2}{|c|}{ Daily activities } & \multicolumn{2}{|c|}{ Return to work } \\
\hline & Number & Per cent & Number & Per cent & Number & Per cent \\
\hline $0-48$ hours & 1 & 1.3 & - & - & - & - \\
\hline 48 hours-1 week & 5 & 6.5 & 3 & 3.9 & - & - \\
\hline 1-6 weeks & 23 & 29.9 & 12 & 15.6 & - & - \\
\hline 6 weeks -6 months & 27 & 35.0 & 35 & 45.4 & 10 & 13.0 \\
\hline 6 months -2 years & 10 & 13.0 & 11 & 14.3 & 20 & 26.0 \\
\hline Failure to achieve result & .9 & 11.7 & 11 & 14.3 & 20 & 26.0 \\
\hline No information & 2 & 2.6 & 5 & 6.5 & 27 & 35.0 \\
\hline
\end{tabular}

was mainly due to loss of libido or was a manifestation of the residual neurological deficit.

Sensory phenomena. The absence of sensory symptoms at final review was strongly associated with a good overall result $(p=0.0008)$. There were also strong correlations of good results with an initial period of hyperpathia $(p=0.0055)$, with the manifestation of Lhermitte's sign $(p=0.0367)$ and with normal perianal sensation on admission $(p=0.0008)$. By contrast, initial hyperpathia correlated with residual sensory symptoms bad enough to interfere with normal function $(p=0.035)$.

Hand function. A simple classification was used to give a composite assessment of hand function. Residual stiffness from lack of use, particularly in the interphalangeal joints, is sometimes a feature of central cord syndrome, so we employed the broad assessments of "stiff and useless" and "stiff and useful" (Table III).

Ability to walk, activities of daily living and return to work. The relevant data are summarised in Table IV. Between six months and two years after injury, $86 \%$ of patients were able to walk unaided, $79 \%$ were performing activities of daily living without assistance and $39 \%$ of patients had returned to work or had regained their preinjury work status. Almost half of the patients $(42.6 \%)$ were able to drive a motor vehicle by six months after the injury.

\section{DISCUSSION}

The mean age of 34.6 years (s.d. \pm 18.1 years; range 14 to 83 years) in the present series is far below that reported for the classic syndrome in other papers (Rand and Crandall 1962; Bosch, Stauffer and Nickel 1971; Shrosbree 1977; Borovich, Peyser and Gruskiewicz 1978; Brodkey, Miller and Harmody 1980), but we found no association between the patient's age at the time of injury and the eventual outcome. In the series of Schneider et al. (1973) the mean age of the patients was 48 years, but in our series half of the patients were under 30 years old at the time of injury.

Although on empirical grounds it might be thought that the neurological deficit seen in the broad group of central cord syndromes we have defined would be similar to that seen in spondylotic myelopathy, clinically the two are quite dissimilar. The latter is usually associated with long tract signs (Epstein et al. 1970; Adams 1976), sphincter function is usually normal, sensory disturbance in both legs and arms commonly occurs and Lhermitte's sign is by no means rare. These features contrast sharply with those found in our series where long tract signs were minimal and neurological deficit was most marked in the upper limbs. An ataxic gait was not typical of our patients at follow-up and most of them, at least initially, had some sphincter disturbance.

Schneider et al. (1973) stated that central syringomyelic lesions may occur in some patients as a result of vascular insufficiency arising from either acute or chronic compression of the anterior spinal artery. Superficially, at least, one might reasonably suppose that central cord injury could possibly lead to post-traumatic syrinx formation; however, there is no evidence to support such a hypothesis. A review of all patients treated in our unit revealed only eight cases of secondary symptomatic syrinx formation; none of these patients initially had a central cord syndrome. The mean time from injury before the onset of symptoms attributable to cystic myelopathy in these eight patients was $\mathbf{4 0}$ months; this agrees closely with the reported average time for the development of this rare, unexplained complication of spinal cord trauma (Barnett et al. 1971). As yet we have not diagnosed a syrinx in the central cord syndrome series; our mean follow-up time was only 30.9 months.

None of our patients had operative decompression of the spinal canal unless we could demonstrate bony impingement upon the cord or a dislocation; in the literature only Brodkey et al. (1980) recommend spinal decompression. The average sagittal diameter of the spinal canal was not reduced in our patients, and this did not appear to be an important indication for operative treatment. It seems that this factor is less significant in the pathogenesis of central cord syndromes than in spondylotic myelopathy (Murone 1974; Adams 1976).

It seems to be widely assumed in papers on classic central cord syndrome that the neuroanatomy and 
SPINAL CORD CROSS SECTION AT C6

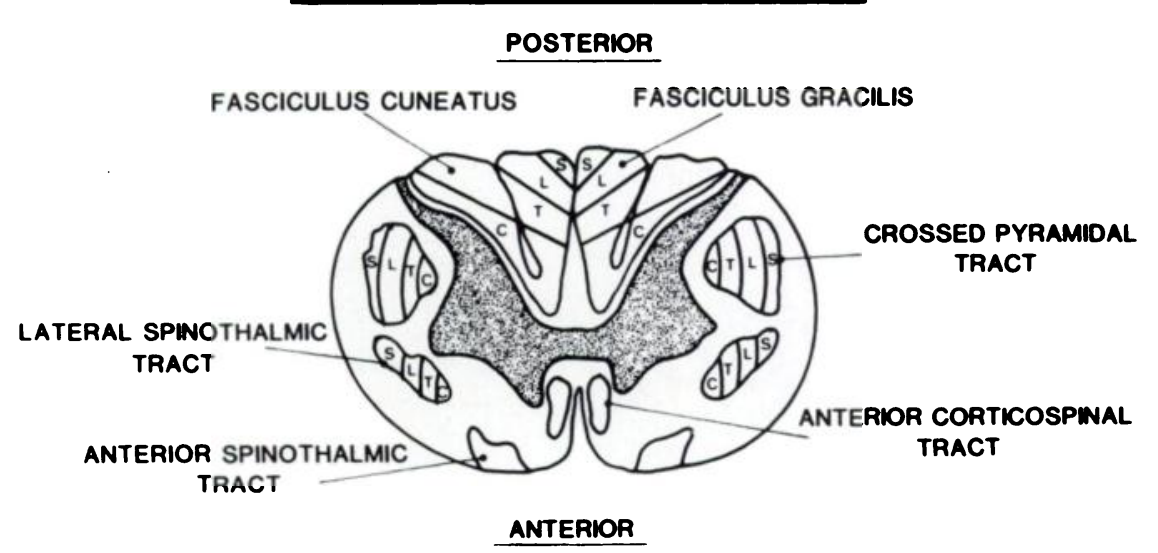

PURE CENTRAL CORD SYNDROME

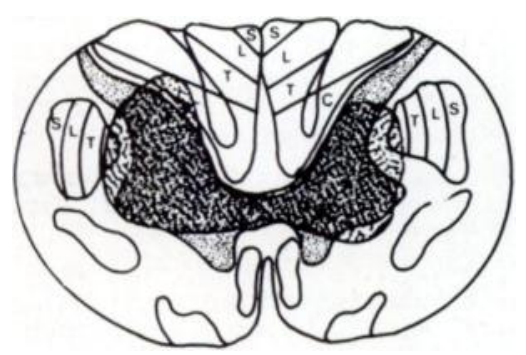

IMPURE CENTRAL CORD SYNDROME

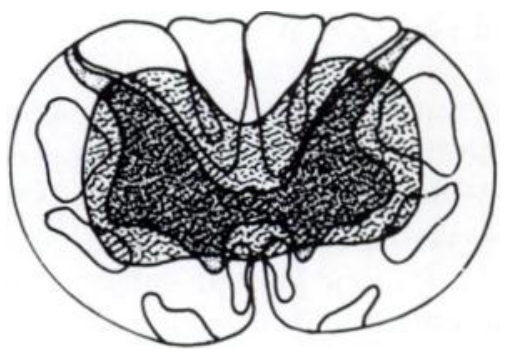

Fig. 9

Diagram of the possible extent of "pure" and "impure" or atypical central cord syndromes. Top, normal cord anatomy; bottom left, pure central cord syndrome; bottom right, an atypical or impure syndrome with centrifugal spread of damage.

neurophysiology of the human spinal cord is accurately known; this is, however, far from the truth. Most authors consider that the upper limb motor deficit in central cord syndromes and, in particular, the residual intrinsic muscle deficit in the hand, result from damage to the most medial fibres of the lateral corticospinal tract which serve the upper limb and hand. If this were so, the topography of a "pure syndrome" might appear as Figure 9 (bottom left) while a more extensive injury, an atypical or "impure syndrome", might involve the more peripheral corticospinal tract fibres which serve thoracic and lumbosacral regions (Fig. 9, bottom right). However, Hopkins and Rudge (1973) have found no evidence for such lamination in man and its occurence in the monkey has also been disputed (Gilman and Marco 1971). Hopkins and Rudge suggest that weakness of the upper limbs results from damage to the fibres as they pass through to synapses in the grey matter; and it is at this level that spatial organisation may apply. Our findings and especially the lack of correlation between intrinsic muscle function and the level of cord injury do not support this contention.

It has been shown that, in higher primates, precise division of the lateral corticospinal pyramidal tract produces loss of movement only in the fourth finger but no other impairment of motor power and no spasticity (Gilman and Marco 1971; Lawrence and Hopkins 1976; Nieoullon and Gahéry 1978). We were unable to discover any information about the division of these tracts in man and it would therefore be wrong to ascribe the reduction in upper limb motor power solely to lateral corticospinal tract injury. Approximately $4 \%$ of pyramidal fibres originate from cortical Betz cells (DeMeyer 1959); the remainder are internuncial or extra-pyramidal fibres but the exact origins of most of them are unknown. Indeed, the function of the lateral corticospinal tract in humans and the origin of the fibres within it are largely unexplained. It therefore seems that there is little point in making deductions about disturbed neuroanatomy from speculative assumptions based on normal neuroanatomy. The descending pathway for the control of micturition is also poorly understood, though it may be mediated by the corticospinal tract (Nathan and Smith 1958).

The actual extent of a given central cord injury cannot be anatomically deduced and the degree of permanent neurological deficit varies considerably. It has been well established experimentally that the central 
part of the cord is the region most susceptible to blunt trauma (Freeman and Wright 1953; Ducker, Kindt and Kempf 1971) and it is thus not surprising that varieties of central cord syndrome are seen in a wide spectrum of cervical fractures and fracture-dislocations as well as in the spondylotic spine. This holds for both pure and atypical syndromes (Fig. 2).

The term "central cord syndrome" was chosen simply to indicate the site of maximum damage to the spinal cord. This study shows that there is considerable variation in the syndrome and extensive overlap with other incomplete syndromes, particularly that of BrownSéquard. It may well be that the only distinguishing feature between these syndromes is the site of maximum tissue damage. It may also be true that the favourable prognostic factors delineated in this study might apply equally to the other incomplete syndromes.

The observed recovery in central cord syndromes is clear evidence that, in many cases, there is no irreversible damage. Those patients who recovered quickly and completely could perhaps best be described as having sustained spinal cord concussion, though even this is compatible with some persistent structural abnormality in the substance of the cord (Ducker et al. 1971). No explanation in terms of disturbed neurophysiology can be offered for the favourable prognosis associated with hyperpathia and Lhermitte's sign; however, the fact remains that their presence in the early recovery phase, along with good hand function and normal perianal sensation, allows the surgeon to be cautiously optimistic.

The permission of our colleagues in the Spinal Injuries Unit to review patients under their care is gratefully acknowledged. Dr P.M. Williamson of the Department of Neurology, Royal North Shore Hospital, gave valuable advice during the study. The line drawings are the work of $\mathrm{Mr} \mathrm{R}$. Drew of the Illustrations Department, Royal North Shore Hospital. We are indebted to Miss S. Tandy-Cockram and Mrs J. Mitchell for valuable assistance in the preparation of the manuscript.

\section{REFERENCES}

Adams C. Cervical spondylotic radiculopathy and myelopathy. In: Vinken PJ, Bruyn GW, Braatman R, eds. Injuries of the spine and spinal cord. Amsterdam etc: Elsevier, 1976:97-112.

Barnett HJ, Jousse AT, Morley TP, et al. Post-traumatic syringomyelia Paraplegia 1971;9:33-7.

Borovich B, Peyser E, Gruskiewicz J. Acute central and intermediate cervical cord injury. Neurochirurgia (Stuttg) 1978;21:77-84.
Bosch A, Stauffer ES, Nickel VL. Incomplete traumatic quadriplegia : a ten-year review. JAMA 1971;216:473-8.

Brodkey JS, Miller CF Jr, Harmody RM. The syndrome of acute central cervical spine cord injury revisited. Surg Neurol $1980 ; 14: 251-7$.

DeMeyer W. Number of axons and myelin sheaths in adult human medullary pyramids: study with silver impregnation and hematoxylin staining methods. Neurology 1959;9:42-7.

Ducker TB, Kindt GW, Kempf LG. Pathological findings in acute experimental spinal cord trauma. J Neurosurg 1971;35:700-8.

Epstein JA, Carras R, Epstein BS, et al. Myelopathy in cervical spondylosis with vertebral subluxation and hyperlordosis. $J$ Neurosurg 1970;32:421-6.

Frankel HL, Hancock DO, Hyslop G, et al. The value of postural reduction in the initial management of closed injuries of the spine with paraplegia and tetraplegia. Paraplegia 1969;7:179-92.

Freeman LW, Wright TW. Experimental observations of concussion and contusion of the spinal cord. Ann Surg 1953;137:433-43.

Gilman S, Marco LA. Effects of medullary pyramidotomy in the monkey: clinical and electromyographic abnormalities. Brain $1971 ; 94: 495-514$

Hopkins A, Rudge P. Hyperpathia in the central cervical cord syndrome. J Neurol Neurosurg Psychiatry 1973;36:637-42.

Lawrence DG, Hopkins DA. The development of motor control in the rhesus monkey: evidence concerning the role of corticomotoneural connections. Brain 1976;99:235-54.

Murone I. The importance of the sagittal diameters of the cervical spinal canal in relation to spondylosis and myelopathy. $J$ Bone Joint Surg [Br] 1974;56-B:30-6.

Nathan PW, Smith MC. The centrifugal pathway for micturition within the spinal cord. $J$ Neurol Neurosurg Psychiat 1958:21:177-89.

Nieoullon A, Gahéry Y. Influence of pyramidotomy on limb flexion movements induced by cortical stimulation and on associated postural adjustment in the cat. Brain Res 1978;149:39-52.

Noordenbos W. Pain. Amsterdam: Elsevier, 1959.

Rand RW, Crandall PH. Central spinal cord syndrome in hyperextension injuries of the cervical spine. J Bone Joint Surg [Am] $1962 ; 44-A: 1415-22$.

Schneider RC, Cherry GR, Pantek H. Syndrome of acute central cervical spinal cord injury with special reference to mechanisms involved in hyper-extension injuries of cervical spine. J Neurosurg 1954;11:546-77.

Schneider RC, Crosby EC, Russo RH, et al. Traumatic spinal cord syndromes and their management. Clin Neurosurg 1973;20:424-92.

Shrosbree RD. Acute central cervical spinal cord syndrome : aetiology, age incidence and relationship to the orthopaedic injury. Paraplegia 1977;14:251-8.

Taylor AR, Blackwood W. Paraplegia in hyperextension cervical injuries with normal radiographic appearances. J Bone Joint Surg [Br] $1948 ; 30-B: 245-8$.

Wolf BS, Khilnani M, Malis LI. Sagittal diameter of bony cervical spinal canal and its significance in cervical spondylosis. Mt Sinai Hosp J Med (NY) 1956;23:283-92. 